Presented at "Symposium on Spallation Nuclear Reactions and Their Applications in Astrol "sics and Radiotherapy," held at the University of Pennsylvania, May 2, 1975.

RADIOACTIVE ISOTOPES ON THE MOON*

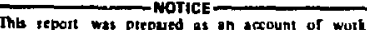
sponeuted by the Undied States Covernment. Neither the United sives goj the Unles Sustes Energ Recesuch smd Develooment Adminlstation, not uny of

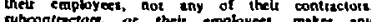

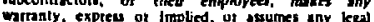

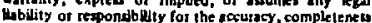
of uxfulares of any intormalion, apperafies, product of proves dieclosed, or cepresents that its ure rould oot

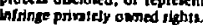

Raymond Davis Jr.

Department of Chenistry, Brookhaven National

Laboratory, Upton, New York

\title{
1. EXPECTATIONS
}

There has been an active interest in observing and accounting for radioactive products produced by cosmic rays in meteorttes since the early suggestion by Bauer (1947) that the helium observed in meteorites was mostly produced by cosmic rays. The first searches for tritium in iron meteorites by Fireman (1958)

$\therefore$ led to the possibility of measuring the cosmic ray exposure ages

3 of meteorttes. By the time of the first lunar landing there were

$\therefore$ a number of laboratories engaged in measuring radioactive and

$\therefore$ stable products produced by cosmic rays in meteorites and earth

$\because$ bound satellites. These studies led to new knowledge of the

$\because$ period of time a meteorite fragment was exposed to cosmic rays. It was found that stone meteorites were exposed for periods of 2

to 30 million years, whereas some fron meteorites were exposed

for many hundreds of millions of years. By studying selected radioisotope pairs it was found that the galactic cosmic ray intensity has been essentially constant for the last 500,000 years ( $\left.{ }^{39} \mathrm{Ar},{ }^{36} \mathrm{Cl}\right)$, and perhaps there has been a lower cosmic ray

Intensity a few bilition years ago $(36 \mathrm{Cl}-40 \mathrm{~K})$. Radioactive products were also applied to studying the gradient in the galactic cosmic ray intensity within the solar system as a result of

$\therefore$ modulation by the magnetic flelds assoclated with the solar wind.

- Many studies were made of the distribution of cosmic ray spall-

$\therefore$ ation products in meteorites and these data were interpreted in

$\therefore$ terms of nuclear cascade processes. Information on these various

$-\cdots$

.. * This work supported by the U.S. Energy Research and Development Administration. 
toplcs can be obtained from reviews and numerous original papers $[1,2]$.

We may ask what new information could be obtained by studying radioactive products in lunar samples? Having a man on the moon made it possible to collect particular samples chosen for the

$\therefore$ problem of interest. In the case of meteorites the original

... surface is lost and the location of the sample within the pre-

-- atmospheric-impact body is unknown. On the moon's surface,

$\div-$ samples can be collected for studying radioactivity distribution

- In the first few mlllimeters of the surface. Fron these surface

:- samples one could learn about solar flare particle fluxes and

- derive information about the variations of these particle fluxes

In the past. Having the surface material one could search for radioactive products collected from space, for example, supernova debris. By digging or boring holes in the lunar soll, samples

$\therefore$ could be obtained at depth, so that we could derive Information

$\div$ about the nuclear cascade processes produced by cosmlc rays in a

$\therefore$ dense medium. This information could be applied to an under-

$\therefore$ standing of mixing processes in the lunar soll. Fixposure age

- dating of rocks could be useful in determining the history of

cratering processes on the moon. It was generally anticlpated

that a wide range of exposure ages would be obtalned. There was

29 - hope that fron a study of certain radioactive products that might

$\rightarrow$ be present in the lunar atmosphere, e.8., tritium and radon, one

- could learn whether these isotopes were desorbed or vented from

- the lunar soll or perhaps were injected into the lunar atmosphere

by solar wind or solar flare particles. Direct counting of lunar

rocks could also measure the primordial radioisotopes $40_{\mathrm{K}}, 238 \mathrm{U}$,

$230 \mathrm{U}$, and $232 \mathrm{Th}$. Using this technique a survey of these primor-

dial radioactive isotopes can be made without sacrificing

- material. These are some of the problems that could be studied.

There was the further vague hope that by entering this new area

- of research something new would turn up.

$\therefore-$

It 18 interesting to recount how the lunar progran was

$\because$ operated, what sort of samples were obtained, and what new lufor-

$\therefore$ mation resulted from studying radioactivities in lunar rocks and

- so11. This report will not be a proper revies, but will give only

- the results of a few studies of special interest from which we can

$\therefore$ see the broad scope of the program.

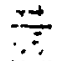

$\because$

2. LUNAR SAMPLES, DISTRIBUTION AND TECHNIQUES

$\because$

$\therefore \quad$ Prior to the first lunar landing the National Aeronautics

- and Space Administration offered the world scientific commatty access to lunar samples and funds for studies within the United states. There was a broad response to the offer and approprtate 
committees were formed to review the proposals and distribute Iunar material. As a result of six missions to the moon a total of $381 \mathrm{kilograms}$ of meterial was recovered. In the early missions detailed information on sample orientation was not generally avatiable. As the program developed there was direct comminication between the astronauts present on the moon, and a panel of $\therefore$ sclentists directing their choice of samples. A broed range of

-- samples was returned consisting of Individual rocks, rock chips, small rocks raked from the surface, surface soll, soil from

trenches, and core and drill tubes driven into the lunar surface.

The materlal was transported in sealed rock bores and the larger

rocks were carried in pouches in the spacecraft. There was a

preliminary examination of selected material that gave useful

data on chemical composition, mineralogical. content, and rare gas

content. The results of the preliminary examination for each

mission were published in Science. A description of each rock

and soll sample was given in a rock catalog for each mission.

- This basic information was avallable to the scientiot, but in

$\because$ general was insuffictent to select the best sample for a partic-

- ular purpose. This was especially true for those studying radio-

- activities where rock orientation and slean surface samples are

- needed. Obtaining the most significant samples required a good

$\frac{3}{75}$ working arrangement between the individual investigator and a

$\div$ mewber of the Lunar Sample Planning Team. This arrangement was

workable but it was difficult for an investigator to discover

$\because$ what samples were avallable and obtain them In a short period of

$\frac{3}{33}$ tre. In addition to the administrative and documentary diffi-

$\frac{3 \mathrm{~J}}{\mathrm{i}}$ culties there was the overriding requirement of a biological

- quarantine placed on lunar materisls. The blological teats

$\frac{3 ?}{i}$ required a period of six weeks before samples could be distrib-

- uted. The biological quarantine was imposed during the first

three lunar missions, Apollo 11, 12, and 14, and after that the

restriction was lifted.

There were some observations that were time dependent and required making measurements during the quarantine pertod. A lowlevel counting laboratory was bullt 50 feet underground in the

:- Lunar Receiving Laboratory to make radioactivity messurements.

if The samples were placed in stainless steel cans, sterilized and

passed to the counting laboratory for direct counting of the

$\because$ garma radiation. The $37_{\text {Ar }}$ ( 35 day half-life) activity measure-

ments were also performed in the Lumar Receiving Laboratory

$=-$ during the quarantine period. Measurements of the ${ }^{222} \mathrm{kn}$ ( 4 day)

present in the gas in the rock boxes were made by extracting the

- gas prior to opening the rock boxes. The searches for magnetic

$\because-$ monopoles, and remnant magnetic properties of rocks were also

$\because$ made during the quarantine period. 
First cliere was the non-dentructive cechnique of observing the gana radiacion directly using a pair of lange sodium lodide crystals. Three laboratortes were engaged in these rasureants, the Lunar Recefving Laboratory already mentioned, a similar prototype system at Oak RAdze National Laboratory, and a 1eboratory at Batcelle-Northwest, Rchland, Washington. Athough there vere other laboratories, these three wade the anjority of the direct counting measurenents. Another approsch was to disaolve the sample, wake chemical separacions of pareteular elenants, and measure the beta and gama radiation using a counting technique deatgnud to have a high selectivity for a particular radiosctive 1sotope. Another approach was to vacuum melt the sapple to extract rare gases, hydrogen and cerhon diaxide. These getes were separated ustag 88 aeparation methods and then placed in proportional counters for mesurenent.

I would 21ke to give the results of a few selected experiments. These will include some observat loas made on the firet . few millimeters of the surface where the effects of solar flare particles are ingortant, some measuraments on Individual rocks.

$\because$ and some studfes of radiosetivities produced deap in the lumar

$\therefore$ soil by galactic cosmic rays.

$\therefore$

$\because=$

3. SORE RESULTS

$\because$

$\therefore 3.1$ At the surface

$=$

- A group of chemists [3] at the Univeratty of calffornia, San - Diego, under the leaderahip of J. R. Arnold measured the depth

$\therefore$ variation of radioactivities in the outer centimeter thick isyer

$\because$ of rock 12002. A vertical slfce and a top alab of the rock was

¡- dissected by carefully grinding off layers, see ELg. 1. Analyoes

- were made by wet chenical aethods to study a variety of leotopes, . namely $10_{\mathrm{Be}}, 22 \mathrm{Na}, 26 \mathrm{Al}, 36 \mathrm{Cl}, 53 \mathrm{kn}, 54 \mathrm{Ma}, 55 \mathrm{Fe}, 56 \mathrm{Co}$, and $57 \mathrm{Co}$. Their results are given in Table 1. The isotope S6Co (77 day

- half-life), was produced by $(p, n)$ reaction (threshold $5.4 \mathrm{kaV}$ ) on the abundant 1sotope, $56_{F e}(91.7 \%)$. Cobalt-56 showed the

$\because$ steepest profile, and is the bese indicator of solar fiare

- protons. The energy spectrum of solar flare protons is known

$\therefore$ - reagonably well from satellite date, and the $(p, n)$ crose sections on $56 \mathrm{Fe}$ are well known. Turthermore, the flares of April 12 and November 3, 1969 contributed 94 percent of the 56 co activity. The contribution from galactic cosmic rays was easentially

- negligible. These Irvestigators compared their 56co depth profile

- from 0.1 to $1.98 / \mathrm{cm}^{2}$ with the depth profile calculated fron solst flare proton intensities and cross-section data. The comparison for this 1sotope was excellent. Simflar calculations for the 
arguments favor no change in the solar luminosity over the lest $10^{8}$ years, although it is entirely posstble that major climatic changes can be actributed co variactons in the solar luminos15y [4]. It would be Inceresting to know whecher there was a change in she solar flare incenatcy, and if $s 0$, the depth variacion of $26 \mathrm{~A}$ and $53 \mathrm{mn}$ ayy be the oniy way of testing for this variacton. Unforcunately, the answer is not clear. The deaturemonce on there leotopes agree reasonably well wich flare particle Cuxes that ate sintiar in energy distribution and spectral shape to those of the last two solat cycles. However, there way be errors in the crostruections (mostly unpublished). Additionally, there is the question of the long perjod orfentation of rock 12002. and che degres of space troston is astious probles. I feel the concluston of essentially constant solar proton intensity-enersy reached is perhaps on $2 y$ true within actor of two of so. This is not of adequate sccuracy to determine whether or not there is a solar derived cause for glaciation. This Ieportant question warranes further atudy, and it would be advisable to use the surface of a very large boulder less likely to have been disturbed.

Another atudy that could give Informution about pase solar intenstetes to the atudy of the ${ }^{14} \mathrm{C}$ profile. Begenan at al. [5] cancurad ${ }^{14} \mathrm{C}$ at three depths $(0-0.5 ; 0.5-2 ; 2-6.5 \mathrm{co})$ in roek 12053 and found the exterior layer was 2.3 tines higher than the two Inaer layers. This high curface value cannot be explatand by $(p, 3 p)$ reaction on oxygen with the save average solar proton

intensicy and enery spectrue that fits the 22\%a, 55Fe, and 54y

- data, that 1s, a 4x incegral flux above $10 \mathrm{kVV}$ of 100 procons $\mathrm{co}^{-2}$ sec $^{-1}$ and an exponential rigldity of $100 \mathrm{~kW}$. To expladn the high ${ }^{14} \mathrm{C}$ value the auchor: asy $=$ flux 3 to 5 times higher, averaged over the past 10,000 years, is neaded. There is also the mundane passtbility that the cross-suctions used are Incorrect. A further poistbility is that the $14 \mathrm{C}$ was produced directis in the photosphere of the sun and inplanted in the surface. A ${ }^{14} \mathrm{C}$ depeh profile was masured by Boeckl [S] on rock 12002, the same rock studied by the Arnold group (F18. 1). His masurements rere ade with a Elner depeh seruceure $(4$ poines $0-9 \mathrm{~m}$ ) than those of Begeman et al. Boeckl obtained a steep profilis that was consistent with a flare proton rigldity that fitted the 22\%a, $55 \mathrm{Fe}$, and $54 \mathrm{kn}$ data, but required a flux a factor of two higher. It is clear that further studies of the $14 \mathrm{C}$ activity in the surface of luar rocks is needed to resolve these Important questions.

It 1s known from the historical record that sunspots were essentially absent over a 70 year pertod from about 1645 to 1715. It would be inceresting to observe this depreseion in the solar activity with radionuclidas in Iunar surface material. However. chere are no radionuclides with a half-life of a few hundred 
years that are suftable for this purpose. Argon-39 (269 $y$ ) has the required half-ilfe but is produced priwarily by neutron reactions on potsssium and calcium. Silicon-32 $(2280 y)$ is another 1sotope with the correct half-life, but it is not produced In good yteld by solar procons on lunar macerials. So $1 t$ is unfirtunate that this solar quiet period cannot be verified quancitatively by radiolsotopes, or conversely, that the radioisotope technique be: cested!

- The surface of the moon is exposed and collects infalling

- material tor billione of years. The temporal record is disturbed In the luner soll by mixing processes rainly as a result of meteorite impects. Mixing by impacts and land slides will be oertous in some locations but at other locations the soll is relatively undisturbed for $10 n g$ perlods of time. There is quantitative Information on these processes based upon measurements of the changes in the gadolintum and samartum 1sotope abundances

$\div$ Induced by neutron capture. Studies on an Apollo 15 core allowed . Buss et al. [6] to conclude that the upper $10 \mathrm{~cm}$ of soil is turned ovar every $0.1 \mathrm{~b}, \mathrm{y}$. and the turnover time at a few meters depth

$\therefore 1 s$ more than $0.5 \mathrm{~b} . \mathrm{y}$.

It 1 is of great interest to search in this material for
$\bar{\vdots}$ debris from supernova explosions and for radioisotopes accumlated from the sun. Fields and his assoctates [7] at Argonne National Laboratory have wade a sea: h for $244 \mathrm{Pu}\left(\mathrm{t}_{1 / 2}-82 \mathrm{m.g}\right.$.) in 12 lunar samples. The lowest 1 iads sec was $10-178244 \mathrm{gu} / 8$ on at few

- gram sample of an Apollo 15 soll. It 18 difficult to estimate

. the expected $264 \mathrm{pu}$ collection rate from supernovas, or cosnte rays.

$\div$ If we take the preaent upper 1 imit to the cosmic ray intensity

$\therefore$ for particles of charge 92-96 of $10^{-11} \mathrm{~cm}^{-2} \mathrm{sec}^{-1}$, assume 10 per

$\because$ cent of the Incoming $244 \mathrm{Pu}$ atoms survive stopping in $1 \mathrm{~s} / \mathrm{cm}^{2}$, and

- collect for a period of $10^{8}$ years, then there may $\mathrm{de} 10^{-18} \mathrm{gu} / \mathrm{P}$

- of linar soll. However, if there were low energy $244 \mathrm{Pu}$ atom arriving as supernova debris a higher concentration could be

$\therefore$ present in lunar so11. It seems clear that further searches for $244 \mathrm{pi}$ should be made with carefully selected samples. There has

- been a grest reluctance to using lunar samples for exploratiory

.- work of this nature in spite of the high interest in this problem.

$\therefore$

: The group at Argonne [7] also made measurements of the

$\because 236 \mathrm{v} / 238_{\mathrm{U}}$ ratio $\left(236_{\mathrm{U}} t_{1 / 2}=23.4 \mathrm{m.y_{* }}\right)$ and the $237_{\mathrm{Np}}\left(t_{1 / 2}=\right.$

$\therefore 2.14 \mathrm{~m} . \mathrm{y}_{*}$ ) concentration in a number of 1 unar soils and rock

samples. One expects a 236U/238U ratio us x 10-9 from s low

- neutron capture on $235_{\mathrm{U}}$ (total $\mathrm{U} 0.1$ to $2 \mathrm{ppm}$ ), and indeed five

- samples are in this range. However, one rock (12073) had a ratio

$=$ of 40-50 $\times 10^{-9}$ and two samples of soil (12070) had ratios of 30-50 $\times 10^{-5}$ (coarse fraction) and $235 \times 10^{-9}$ (total sample). These very high ratlos cannot be explained by nuclear reactions on $238 u$ such as the $(n, 3 n)$ or $(p, t)$ reactions. They require a 
h1gher production rate sometime in the past, or some other source for the $236 \mathrm{U}$. If it were from an increased solar or galactic cosmic ray intensity over long periods of time, all the exposure ages derived from present cosmic ray fluxes would be shortened considerably. However, if there were short perlods of verg high particle fluxes exposure ages would not be affected. The fact that $53 \mathrm{Mm}$ activities are within a factor of two of the concentrations expected from preseni day solar and galactlc cosmic ray fluxes requires that fluxes as high as indicated by $236 \mathrm{U}$ concentrations did not occur during the last $10^{7}$ years. This interesting

$\therefore$ result needs a clear explanation and 1t would be very useful to have additional measurements on both rock and soll samples.

\subsection{At depth}

During the last three missions to the moon the astronuts recovered long colume of the lunar soll with a spectin coring drill [8]. The length of the three cores were $2.4,2.4$, and 2.9 meters. Obtaining these long cores was a major achievenent In sampling the lunar surface. These and the shorter drive tubes are our only samples that give a view of regolith stratigraphy. Studies on these cores ubing a variety of techniques, gadolinium and samarium isotope mass spectronetry, rare gas lsotope analyses, fossil track distributions, chemical analysis, and afnerological studies have lead to new knowledge of the history of the lunar regolith. I would like to confine my discussion to an in situ

$\therefore$ measurement of the neutron flux distribution and some radio-

isotope measurements that were made on these cores.

$\because$

A basic factor in understanding the gadolinium and samarium 1sotope distribution changes as a result of neutron capture is to know the present-day neutron fluxes produced in the luar soil by

$\div$ cosmlc ray interactions. The flux distribution was calculated

$\because$ theorrtically by Iingenfeltex, Canfleld, and Hampel and by Armstrong and Alsmiller [9], and it was of great interest to measure the flux experimentally. The measurement was made by a special probe designed by Don Burnett (CIT) that was introduced Into the hole in the lunar regolith after the Apollo 17 coring dr111 was renoved. After insertion a mica fission track detector

- was rotated over a $235_{U}$ foil, and a plastic track detector was rotated over a $10_{B}$ foil to register slow neutron captures. The probe was in place registering the flux for 49 hours. The results [10] for both target elements showed a sharp rise from the surface to a broad peak at a depth of $100-160 \mathrm{~g} / \mathrm{cm}^{2}$ and slow decrease with increasing depth. The shape of the curve fitted the theoretical curve very well, see F1g. 2. The cotal neutron capture rate in $235 \mathrm{U}$ was $11 \pm 17$ percent $10 \mathrm{wer}$, and in $10_{\mathrm{B}}$ it was $19 \pm 13$ lower than the theory of Lingenfelter et al. predicted. 


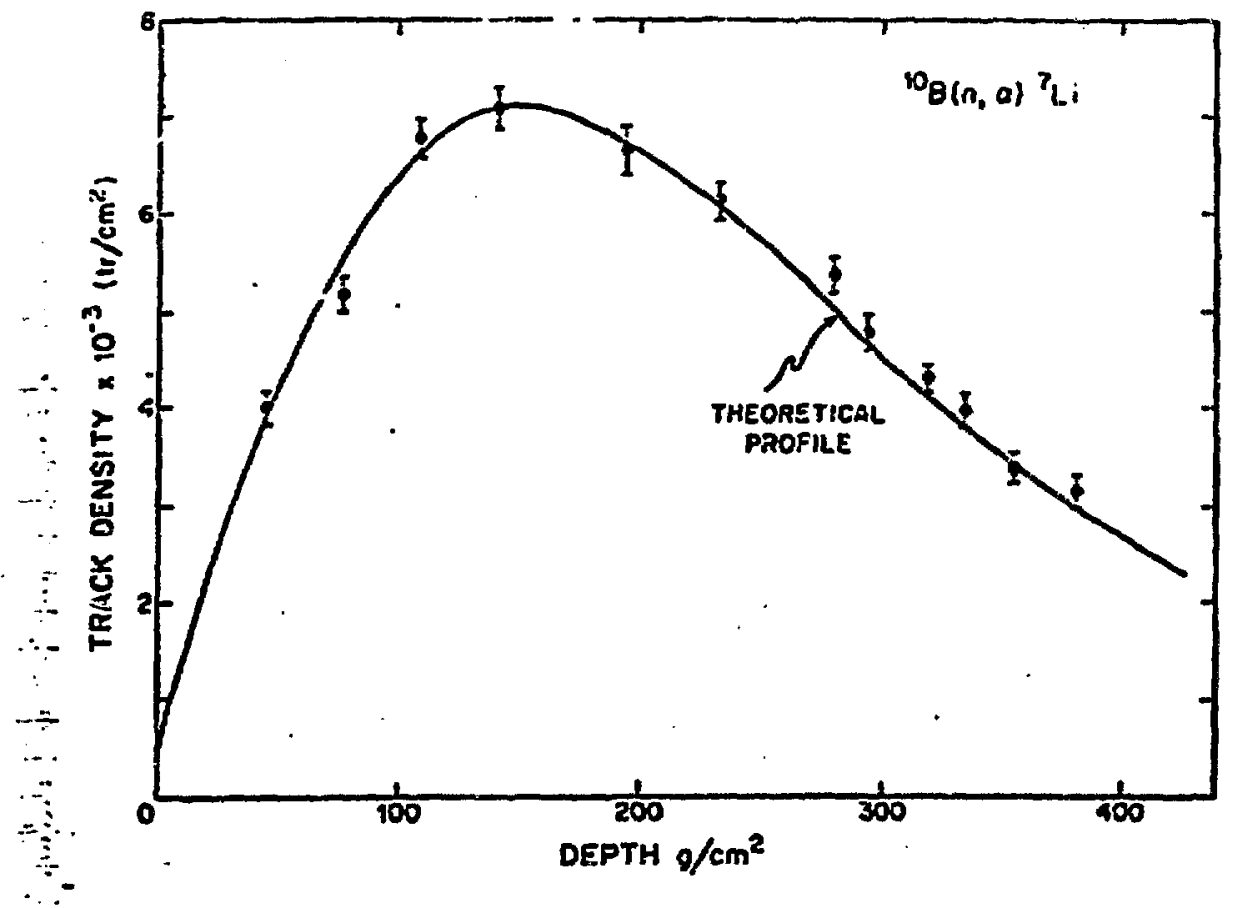

$\therefore$ Fig. 2. Neutron depth profile obtalned by Hoolum and Burnett [10]

$\therefore$ compared to the theory of Lingenfelter et al. [9].

$\therefore-$

$\div$

The results for $10_{B}$ normailized to the theory are shown in Eig. 2.

$\div \quad$ By combiniag the neutron flux distribution in the lunar soll

$\therefore$ : th measurements of the total neutron fluences (Flux $X$ tIme)

$\therefore$ measured by $157 \mathrm{Gd}$ captures and the regolith depth $(4-5 \mathrm{~m})$ inferred from observations, it has been concluded that the total fluence

$\therefore$ is a factor of 2-3 times lower than expected for a uniformly mixed soli exposed for 3.8 billion years. Workers in this field

- have made a great issue of this problem $[10,11]$. The various

- suggested solutions include (1) the regolith is not well mixed,

(2) the regolith is not as deep as is thought, (3) the cosmic ray intensizy averaged over the last 3-4 bilifion years is lower than

- present intensities, (4) large quantities of lunar 8011 are

$\because$ ejected by metero11 impacts [12] $\left(40-100 \mathrm{~cm} / 10^{9} \mathrm{y}\right)$, or (5) some

$\because$ combination of these or other discrepancies give an apparent reduction in neutron fluences. These observations give an

$\therefore$ Interesting insight into the development of the lunar regoltth, a

- topic of broad significance in the evolution of the sol.ax system.

It wits of Interest to have a measure of the fast neutron flux generated in the so11 by cosmic rays. The 35 -day isotope $37_{\mathrm{Ar}}$ is 


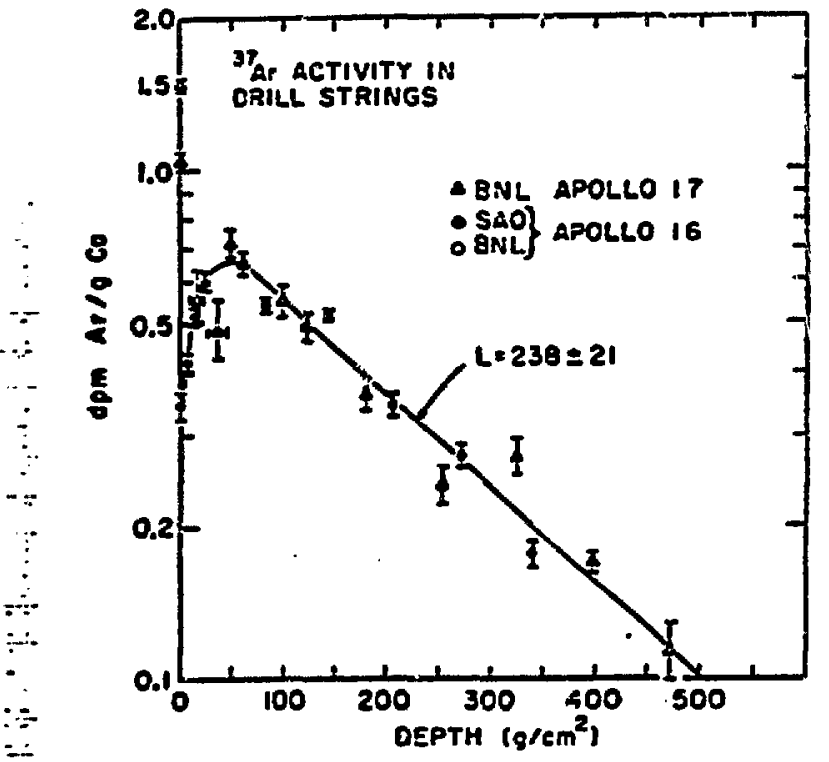

Fig. 3. ${ }^{37} \mathrm{Ar}$ depth profile measured in the Apollo 15 and $17 \mathrm{dr} 111$ cores $\{14,15\}$.

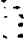

$\because$ in Ideal one for this purpose. It is produced by the reaction

$\div 40 \mathrm{Ca}(n, a) 37_{\mathrm{Ar}}$ on the abundant element calctur ( $7-12$ perceat).

-: Argon-37 is a radiolsotope that is easily extracted and couned

anking it possibje to perform measurements on modest amouncs of sample (1-2 g). The production cross section has been measured.

$\because$ The excitation function shows an effective threshold at about

$3 \mathrm{MeV}, \mathrm{rlging}$ to broad maximum at $6 \mathrm{MeV}$ (205 mb) and then it

- drops slowly with 1rcreasing energy (138 $\mathrm{mb}$ at $14 \mathrm{MeV}$ ) [13]. The

:- $37 \mathrm{Ar}$ activity as a function of the depth was measured 1 ti the Apollo 16 core as a jolnt project between Salthsonian Astrophysical Observatory [14] and Brookhaven Vational Laboratory [15].

- Only the deeper portlons of the Apollo 17 core were analyzed

$\because$ because the upper portions of this core were not opened in time

$\therefore$ for the measurements. All samples were analyzed for calcium so

$\therefore$ that the measurements for the two missions could be compared. A

$\because$ plot of dpm $37_{\mathrm{Ar} / 8 \mathrm{Ca}}$ is given in F1g. 3. The $37_{\mathrm{Ar}}$ production exhlbits a steep rise with depth, corresponding to the developwent

$\because$ of the nuclear cascade, reaching a maximun at a depth of about

$\therefore 50 \mathrm{~g} / \mathrm{cm}^{2}$, and then it dropped exponentially with an atteuuation

$\therefore$ length of $240 \pm 20 \mathrm{~g} / \mathrm{cm}^{2}$. This general behavior is expected from the nuclear cascade process in the lunar soll [16]. There were no solar flares Immediately before the Apollo 16 mission, so these measurements give a valid $37_{\text {Ax }}$ production rate from galactic 
cosmlc rays. Kornblum and his associates [17] have made calculations of the $37_{\mathrm{Ar}}$ depth profile with a defined neutron source function, the neutron moderating factors derited from the lunar composition (ANISN neucron transport code), and che measured $40 \mathrm{Ca}(n, a){ }^{37}$ Ar excitation function. Their calculated profile f1ts the measurements, and they obtain a total neutron production rate in lunar soll of $26 \pm 4 \mathrm{~cm}^{-2} \mathrm{sec}^{-1}$ by normalizing the calculations to the experimental reasurements. This value is higher than that of Lingenfelter et al. and Armstrong and Alsmiller, $16 \pm 5$ and 17.5, respect ively.

The Apollo 17 mission followed only 124 days after the intense solar flare of Aug. 4-9, 1972. This flare was the most Intense flare ever observed, similar in magnitude to the great

- flare of 1956 . This flare produced approximately $2 \times 10^{10}$ protons/ $\mathrm{am}^{2}$ with energy above $60 \mathrm{MeV}$. The effects of this flare

- were clearly observed in many samples returned frow the Apolito 17

- mission. The $37 \mathrm{Ar}$ activities were found to be very high in the samples from the surface (depth $0-5 \mathrm{~g} / \mathrm{cu}^{2}$ ), but samples at greater -. depths $\left(>50 \mathrm{~g} / \mathrm{cm}^{2}\right.$ ) were not affected. The flare protons Iateract

$\therefore$ at the surface to produce $37_{\mathrm{Ar}}$ by the reaction $40 \mathrm{Ca}(\mathrm{p}, \alpha){ }^{37} \mathrm{~K}\left(\beta^{+}\right.$-

$\therefore$ decay) 37 Ar. During the Aug. 1972 flare the production rate at

the surface was over 400 times the normal coamis ray production rate.

$\therefore$ The long lived argon isotope, ${ }^{39} \mathrm{Ar}\left(t_{1} / 2=265 \mathrm{y}\right)$, was also
$\therefore \quad$ measured on the Apollo 16 and 17 cores $(14,15)$. This isotope is

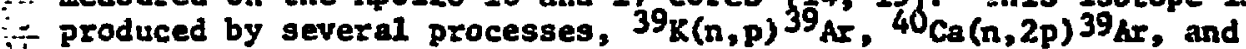

$:-$ by spallation of iron. The excitation functions for the neutron

$\therefore$ reactions have not been measured so the relative cosmic ray production from these various processes cannot be sorted out.

- The depth distribution curve exhibits the characteristic increase

- from surface values (factor of 1.6 ) reaching a maximum at a depth of $50 \mathrm{~g} / \mathrm{cm}^{2}$ and then dropping exponentially with an atcenuation

$\therefore$. length of $166 \mathrm{~g} / \mathrm{cm}^{2}$. The general behavior is in agreement with expectation.

It is of great interest to observe the depth profile of a long lived redioactive isotope to search for long period variations in solar activity or galactic cosrofc ray intensities. As mentioned earlier $53 \mathrm{Mn}$ is an ldeal isotope for this purpose. It $\rightarrow$ has a long half-life, $3.7 \times 10^{6}$ years, and it can be measured by a veutron activation technique that requires only a $0.2 \mathrm{~g}$ sample. This isotope is made at the surface by low energy protons mainly by the $56 \mathrm{Fe}(p, \alpha)^{53 \mathrm{Mn}}$ and $56 \mathrm{Fe}\left(n, p^{3 n}\right)^{53} \mathrm{Mn}$. Imanura et al. [18] measured the $53 \mathrm{Mn}$ depth profiles in the Apollo 15 and 16 cores. The solar protoil produced $53_{\mathrm{Mn}}$ is very high at the surface, dropping rapidly with depth to a depth of $2 \mathrm{~g} / \mathrm{cm}^{2}$, see $F I_{g}$. 4 . Below a depth of $10 \mathrm{~g} / \mathrm{cm}^{2}$ it decreases exponentially with an attentuation length of $220 \pm 50 \mathrm{~g} / \mathrm{cm}^{2}$. The results agree we?1 


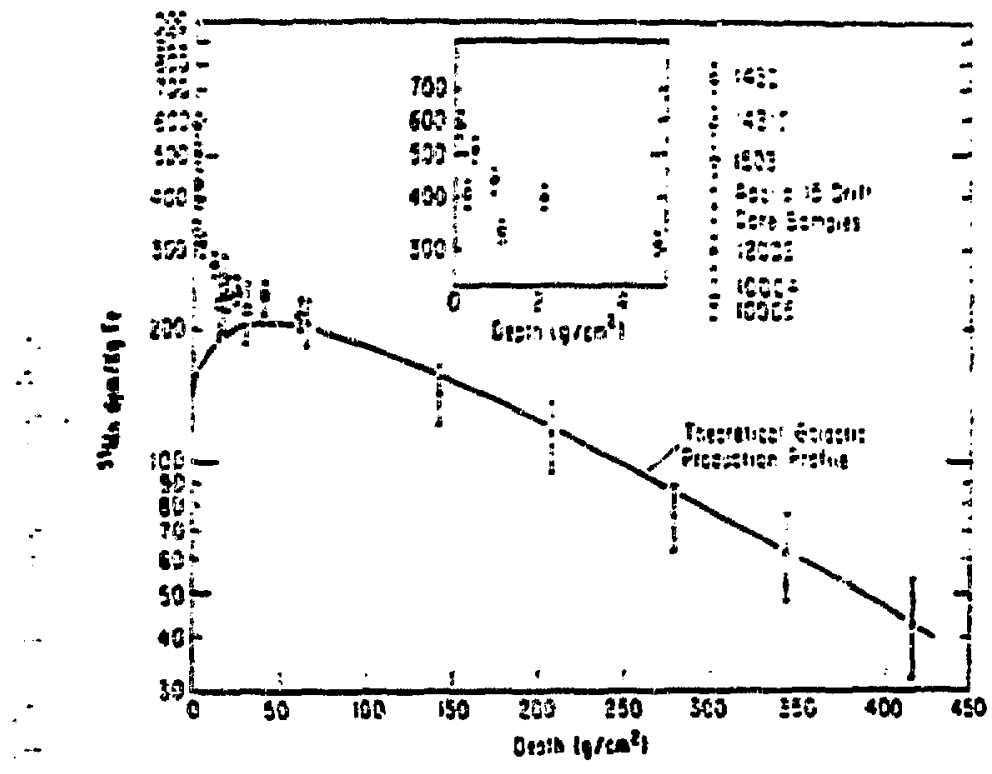

$=$

F18. 4. $53 \mathrm{kn}$ depth proftle of 1wanura et 1 . obtained on the Apolio 15 dr111 core, soil and rock sasples $[3,18]$.

Wth the model calculations of Reedy and Arnold [16]. It was

- concluded that the soil colum has renained undisturbed for the

- lase 5 willion years, consistent with the Gd isotope conclusion: zentosed earlier that extend over a much longer period of time.

It would be interesting to conpare the depth prefile of various radiolsotopes with actual weasurements with accelerated protons and alpha particles. In the past there has been a number

$\therefore$ of these thick target bombardments, the first being B. S. P. Shen's bombarduent of an Iron target $30 \times 30 \times 90$ cm with $3 \mathrm{GeV}$ protons. The results of these early bosbardments are sumarized - In a review by kohman and Bender [2]. Two studies have been made recently with thick targets of sirulated lunar soll. Bar and Hert [19] studied thermoluainescence of Dinerals as a function of the depth in a target $30 \times 30 \times 140 \mathrm{~cm}$ bobarded with $600 \mathrm{skeV}$ protons. Lyman [20] measured $37 \mathrm{Ar}, 39 \mathrm{Ar}, 42 \mathrm{Ar}$, and trit tum activity distribution in a simulated lunar target $20 \times 20 \times 43 \mathrm{~cm}$ bombarded by $600 \mathrm{MeV}$ protons. Experiments of this type require counting numerous samples and it is further necessazy to perform the measurements at a series of energies. In view of the enormous effort involved, most experimenters are discouraged. Also the basic nuclear cascade process is understood, and it does not seem worth the effort at the present time to establish the detailed 
parameters involved.

\subsection{Individual rocks}

The largest amount of data on radioactivities in lunar materlals was obtained by a few laboratorles that measured gama radiation by NaI scintillation counters. Large pure activated NaI(TI) cryst 31 scintillation detectors were developed Industrlally and a number of laboratories devised sophisticated low-level counting arrangements for measuring lunar and environmental

. sampies. This approach has the decided advantage of being able to measure lunar samples without affecting then in any way. Once the elaborate counting facility was built a large number of samples can be surveyed. In fact the accumularion of data was limited by the ability of the curator's office to process the sample, especially during the quarantine perlod. One extremely useful observation that was made immediately was that lunar rocks are relatively $10 \mathrm{w}$ in the volatile element potassium. If a plot of the ratio $\mathrm{K} / \mathrm{U}$ versus $\mathrm{K}$ concentration is made, it can be shown that Igneous earth rocks, lunar rocks, and various meteorite classes, eucrites, carbonaceous chondrites and ordinary chondrites fall into distinct groups [21]. This useful plot not only sorts out solar system materials but also allows a classification of lunar basalts, solls, highland rocks, and brecclas. These

. measurements of primordial radioactive elements also demonstrated that the Th/U ratio for lunar rocks is 3.8 , almost identical to the ratio generally observed for earth rocks [21, 22].

The usual cosmogentc radioactivities measured were: $22 \mathrm{Na}$ $(2.6 \mathrm{y}),{ }^{26 \mathrm{Al}}\left(3.7 \times 10^{6} \mathrm{y}\right),{ }^{46} \mathrm{Sc}(84 \mathrm{~d}),{ }^{48 \mathrm{~V}}(16 \mathrm{~d}),{ }^{5 I_{\mathrm{Cr}}} \mathrm{C}(28 \mathrm{~d})$, $54 \mathrm{Min}(303 \mathrm{~d}), 57 \mathrm{Co}(270 \mathrm{~d}), 58 \mathrm{Co}(71 \mathrm{~d})$ and $60 \mathrm{Co}(5.3 \mathrm{y})$. The activity levels are dependent upon the chemical composition of rock, and where relevant cross-sections and chemical analyses are known, the agreement between measured and calculated activities is satisfactory. There is interest in deriving information about cosmic ray intensities in the past and about Iunar surface events from the pair of isotopes $22 \mathrm{Na}$ and ${ }^{27} \mathrm{Al}$. These isotopes are produced by various reactions on the elements $\mathrm{SI}, \mathrm{AI}, \mathrm{Mg}$, and Na. Yokayama et al. [23] and Keith and Clark [24] have attempted to normalize the observed activitles by adopting a production rate for each element. Their techniques are useful for selecting rocks with exposure ages comparable to the haif-11fe of $26_{\mathrm{Al}}$, the so-called undersaturated rocks.

The solar flare of Aug. 4-9, 1972 produced dramatic increases in activity levels of all measured isotopes with half-1ives shorter than a few years. By careful measurements of varlous isotopes with well measured excltation functions it was possible to determine the average rigldity parameters and fluxes that 
characterlze the energy spectrum of the solar flare protons from this event $[21,25]$. Also there is evidence from the measurements on rock surfaces at varlous angles of inclination that the flare particles were anisotroplc [25].

I might conclude by some remarkg about cosmic ray exposure ages. Since lunar rocks are exposed on the surface, one can apply mass-spectroscoplc measurements of the abundant rare gas spallation products 1 ike ${ }^{3} \mathrm{He}$ or ${ }^{38} \mathrm{Ar}$ to derive exposure ages, assuming a constant production rate for all samples. Helium-3 exposure

$i$ ages are questionable because of the loss of both tritium and $\because-$ hellum. A much more rellable method is to determine the temperature release pattern of the argon 1sotopes from neutron activated

samples following the technigue now common in $40 \mathrm{Ar} \div 39 \mathrm{Ar}$ dating.

In this method the release of spallation $38 \mathrm{Ar}$ from calcium can be

related to the $37_{\mathrm{Ar}}$ produced by $(n, \alpha)$ reaction on $40 \mathrm{Ca}$. By

adopting an assumed 38 Ar cosmic ray spallation production rate on

calcium $\left(1.4 \times 10^{-8} \mathrm{~cm}^{3} \mathrm{STP} / \mathrm{g} \mathrm{Ca} \cdot 10^{6} \mathrm{y}\right)$, the exposure age can be

$\div$ obtained. The usual assumption of constant spallation production

For all samples is of course not correct, as there is a change in

$\therefore$ production rate with depth. Another method of determining expo-

sure ages depends on mass spectroscoplc measurements of $8 \mathrm{I}_{\mathrm{Kr}}$

$\div\left(t_{1 / 2}=2.1 \times 105 \mathrm{y}\right)$, a spallation product of $\mathrm{Sr}, \mathrm{Y}$, and $\mathrm{Zr}$. The

method depends upon the rock being exposed for a period long

compared to the half-life of $81 \mathrm{Kr}$ permitting the concentration of

81 Rr to be used for the production rate in the sample. The con-

centration of ${ }^{81} \mathrm{Kr}$ relative to the stable isotope $83 \mathrm{Kr}$ is used to

determine the exposure age. It 1s assumed that tine production

cross section of $81_{\mathrm{Kr}}$ is equal to the average of the $80 \mathrm{Kr}$ and $82 \mathrm{kr}$

production cross-sections. One would expect the relative produc-

tion cross-sect lons of $81 \mathrm{Kr}$ and $83 \mathrm{Kr}$ to depend upon target element,

- and thereby depend upon the $S r, Y$, and $Z r$ composition of the rock.

However, in spite of this obvious difficulty, this method is held

In high esteem.

Exposure ages of lunar rocks vary considerably, as one might

expect from random impacts on the lunar surface so prec1se exposure age measurements are not particularly required. There

$\%$ are numerous exposure age measurements of variable quality

throughout the lunar literature. The range of expesure ages are

$\therefore$ from 600 mt11tion years to rocks that have not been exposed long

- enough for $26_{\mathrm{Al}}$ activity to reach saturation, about 1 milifion

years.

4. Conclusions

It is Interesting to look back over the accomplishments of the last five years of studying radloactivities in lunar samples, and to Inquire whether we have leamed anything new. There is no 
question that an enormous amount of new Information has resulted from studying lunar samples and we can address our inquiry at three levels: (1) were the new observations consistent with or do they support earlier views, or (2) were there some surpriseg that now need confirmation, or (3) did we discover something totally new. I believe the studies of radioactivities in lunar materlal are essentially characterized as being consistent with earliex knowledge, but there are a few Interesting results that need further work.

First, concerning the production of radioactivities by galactic cosmic rays. The measurements in individual lunar rocks and at depth in the lunar soll are consistent with what was already known. The measurements of the depth profile of radioactive producis with half-lives in the order of months to millions of years agree reasonably well with theoretical calculatinns of the nuclear cascade processes and present galactic cosmic ray $\therefore$ intensitles and energy spectra. The lunar results are consistent with a constant cosmic ray flux. However, the best test of the constancy of the galactic cosmlc ray flux are the clder measurements of $39 \mathrm{Ar}, 36 \mathrm{cl}$, and $40_{\mathrm{K}}$ in iron meteorites. It seems unlikely that further measurements on Iunar material will lead to any new knowledge on this question. However, one can see that there w111 be further interest in applying our knowledge of - cosmlc ray Interactions in lunar material to understanding mixing - processes in the lunar soil, and possibly measuring accurate exposure ages of lunar rocks.

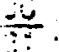

Studies of the activities on the surface of lunar rocks and i2 surface soll samples have produced some interesting results. The 3 question of the solar flare intensity in the last $10^{6}$ or $10^{8}$ years is an important question that needs further study. New measurements of the depth profile are needed of $22 \mathrm{Na},{ }^{14} \mathrm{C}$ and $53^{3 \mathrm{~m}}$ on $j$ the surface of large rocks likely to be fixed in their position for perlods 1onger than 107 years. Add1tional studies of $236 \mathrm{~J}$ and $237 \mathrm{~Np}$ are certalnly needed. It is very important to under$\therefore$ stand how some samples can have 10 to 100 times higher concentrations of $236 \mathrm{U}$ than others. Perhaps $236 \mathrm{U}$ is the on $1 \mathrm{y}$ isotope with $\therefore$ a half-life long enough to retain the effects of events that occurred 108 years ago.

$\because$

Finally a thought on the use of Iunar samples for exoloratory

work. Experiments like the ones searching for $244 \mathrm{Pu}$, and super heavy elements have not been espectally encouraged. It mag be a few decades before new samples are obtained from the moon, but when lunar exploration is revived our present closely guarded collection will be cnly of secondary interest. I feel the present collection should be more avallable to the sclentific community and more emphasis should be placed on signiflcant exploratory studies. 


\section{REFERENCES}

The abbreviation PLSC-2 stands for Proc. 2d Lunar Sc1. Conf., Geochim. Cosmochim. Acta, Suppl. 2.

1. O. A. Schaeffer, Ann. Rev. Phys. Chem. 13, 151 (1962); M. Honde and J. R. Arnold, Handbuch der Physik XIV1/2, p. 613 (1967), Springer-Verlag, Berlin.

2. T. P. Kohman and M. I. Bender, High-Energy luclear Reactions In Astrophysics, ed, by B. S. P. Shen, Benjamin Press, 1967.

3. R. C. Finkel, J. R. Arnold, M. Imamura, R. C. Reedy, J. S. Fruchter, H. H. Loosli, J. C. Evans, and A. C. Delany; PLSC-2, Vol. 2, p. 1773 (1971).

4. A. G. W. Cameron, Rev. Geophys. and Space Fhysics 11, 505 (1973).

5. F. Begeman, W. Born, H. Palme, E. Vilesek, and H. Wanke, PLSC-3, Vo1. 2, p. 1693 (1972); R. S. Boeckl, Earth and Planetary Se1. Letters 16, 269 (1972).

6. G. P. Russ III, D. S. Burnett, and G. J. Hasserburg, Earth and Planetary Sci. Letters 15, 172 (1972).

7. P. R. Flelds, H. Diamond, D. N. Netta, and D. J. Rokop, PLSC-4, Vol. 2, p. 2123 (1973), contains earlier references.

8. D. S. Woolum, D. S. Burnett, and C. A. Bauman, Apo110 17 Preliminary Science Report NASA SP-330. These reports are a very useful source of general information on each mission.

9. R. E. Lingenfelter, E. H. Canfleld, and V. E. Hampel, Earth and Planetary Sc1. Letters 16, 355 (1972); T. W. Armstrong and R. G. Alsmiller, PLSC-2, Vo1. 2, p. 1729 (1971).

10. D. S. Woolum and D. S. Burnett, Earth and Planetary Sci. Letters 21, 153 (1974); D. S. Burnett and D. S. Woolum, PLSC-5, Vo1. 2, p. 2061 (1974).

11. O. Eugster, F. Tera, D. S. Burnett, and G. J. Wasserburg, Earth and Planetary Sci. Letters 8, 20 (1970); G. Price Russ III, ibid, 19, 275 (1973) and references therein.

12. E. L. Fireman, PLSC-5, Vol. 2, P. 2075 (1974).

13. J. W. Barnes, B. P. Bayhurst, B. H. Erkkfla, J. S. Gilmore, N. Jaimle, and R. J. Prestwood, J. Inorg. Nucl. Chem. 37,

- 399 (1975).

=- 14. E. L. Elreman, J. D'Amlco, and J. De Felice, PLSC-4, Vol. 2,

$\because$ p. 2131 (1973).

$\therefore$ 15. R. W. Stoenner, R. Dav1s Jr., E. Norton, and M. Bauer,

PLSC-5, Vol. 2, p. 2211 (1974).

16. R. C. Reedy and J. R. Arnold, J. Geophys. Res. 77, 537 (1972).

- 17. J. J. Kornblum, E. L. Fireman, M. Levine, and A. A. Aronson,

$\therefore \quad$ PLSC-4, Vol. 2, p. 2171 (1973); J. J. Kornblum, Thesis, State Unfversity of New York at Stony Brook, 1975.

18. M. Imamura, R. C. FInkel, and M. Wahlen, Earth and Planetary Sc1. Letters 20, 107 (1973); M. Imamura, K. Nishilzumi, M. Honda, R. C. Finkel, J. R. Arnold, and C. P. Koh1, PLSC-5, Vo1. 2, p. 2093 (1974). 
19. K. Bar and W. Herr, Earth and Planetary Scl. Letters 22, 188 (1974).

20. W. J. Iyman, Preliminary Report, Chemistry Department, Brookhaven National Laboratory, Upton, N.Y. (1971).

21. J. S. Eldridge, G. D. O'Relley, and K. J. Northcutt, PLSC-5, Vol. 2, 1025 (1974) and earlier references therein.

22. J. E. Keith, R. S. Clark, and I. J. Bennett, PLSC-5, Vol. 2, 2121 (1974) and earlier references therein.

23. Y. Yokoyama, J. L. Reyss, and F. Guichard, PLSC-5, Vol. 2, p. 2231 (1974).

24. J. E. Keith and R. S. Clark, PLSC-5, Vol. 2, p. 2105 (1974).

25. L. A. Rancitell1, R. W. Perkins, W. D. Felix, and N. A. Wogman, PLSC-5, Vo1. 2, p. 2185 (1974).

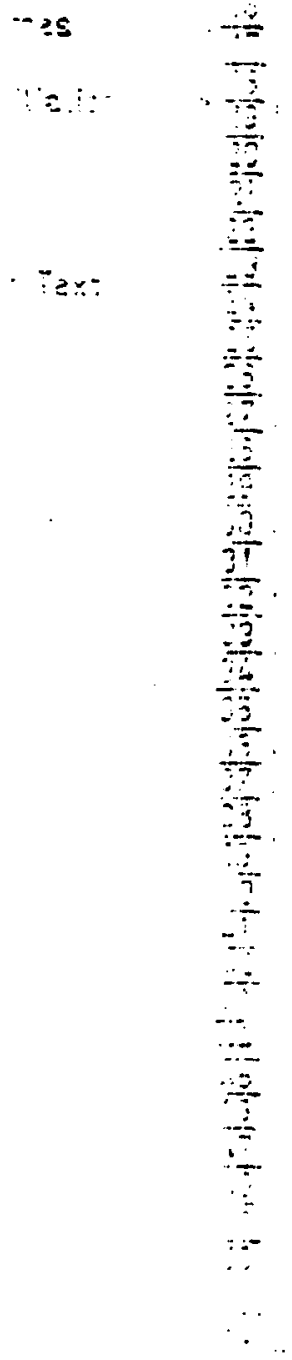

